\title{
Rendimento de feijão e alterações no pH e na matéria orgânica do solo em função de doses de composto de resíduo de algodão
}

\author{
Yield of bean plant and changes in $\mathrm{pH}$ and soil organic matter as a function of doses of \\ compost cotton waste
}

\author{
Sílvio Júnio Ramos ${ }^{\mathrm{I}}$ Daniel Soares Alves ${ }^{\mathrm{II}}$ Luiz Arnaldo Fernandes ${ }^{\mathrm{III}}$ \\ Candido Alves da Costa ${ }^{\text {III }}$
}

\begin{abstract}
O objetivo do presente trabalho foi avaliar o RESUMO rendimento de feijão e as alterações no $\mathrm{pH}$ e na matéria orgânica do solo após a aplicação do composto de resíduo de algodão. Para tanto, instalou-se o experimento em condições de campo, em um Argissolo Vermelho-Amarelo. $O$ delineamento experimental foi em blocos ao acaso com cinco tratamentos constituídos por doses $\left(0,20,40,60,80 t h^{-1}\right)$ de resíduo de algodão compostado oriundo da indústria têxtil, com cinco repetições. Verificou-se que a aplicação do resíduo de algodão compostado promoveu melhoria nas características produtivas do feijoeiro submetido ao manejo orgânico e elevou os valores de pH e matéria orgânica do solo. Desse modo, o composto utilizado mostrou-se como uma alternativa para a adubação da cultura.
\end{abstract}

Palavras-chave: resíduo orgânico, composto orgânico, Phaseolus vulgaris.

\section{ABSTRACT}

The objective of this research was to evaluate the yield of bean plants and changes in $\mathrm{pH}$ and soil organic matter after compost cotton waste application. An experiment was carried out in an Acrisol. The experimental design was of randomized blocks with five levels of cotton waste compost $\left(0,20,40,60,80 \mathrm{~h} \mathrm{ha}^{-1}\right)$ from the textile factory, in five replications. The application of the cotton waste compost promoted increase in the growth and productive characteristics in bean crop, and increased the $\mathrm{pH}$ values and soil organic matter. Thus, the compost showed as an alternative for fertilization of the culture.

Key words: organic residue, organic compost, Phaseolus vulgaris.
A cultura do feijoeiro é disseminada em todo o país. Além disso, possivelmente ela tenha um significado social mais alto na composição da agricultura brasileira, sendo constantemente associada ao agricultor familiar como cultivo de subsistência e referência para a alimentação da população urbana e rural(CHIARADIA \& GOMES, 1997). Nos últimos anos, a utilização de resíduos orgânicos urbanos e agroindustriais tem sido uma prática usual na tentativa de aproveitamento desses subprodutos na agricultura, possibilitando a reciclagem de nutrientes. Segundo SEITER \& HORWATH (2004), a busca pela melhoria na qualidade de produção e a necessidade de reduzir custos têm contribuído para aumentar o uso de resíduos orgânicos na produção agrícola. No entanto, estudos que relatam o aproveitamento do resíduo de algodão proveniente da indústria têxtil como composto orgânico na agricultura são ainda escassos.

Quanto aos benefícios gerados pela adição de materiais orgânicos nas propriedades químicas do solo, MELLO \& VITTI (2002) relatam como relevantes o aumento do $\mathrm{pH}$ e dos teores de nutrientes no solo. De acordo com COSTA et al. (2005), o processo de compostagem tem sido utilizado como alternativa para a disposição ambientalmente correta de resíduos oriundos de diferentes atividades agrícolas, agroindustriais e industriais. Assim, o objetivo do

'Departamento de Ciência do Solo, Universidade Federal de Lavras (UFLA), 37200-000, Lavras, MG, Brasil. E-mail: silviojramos@gmail.com. Autor para correspondência.

"Merck S/A, Terra Rica, PR, Brasil.

IIIInstituto de Ciências Agrárias, Universidade Federal de Minas Gerais (UFMG), Montes Claros, MG, Brasil. 
presente trabalho foi avaliar o rendimento de feijão e as alterações no pH e na matéria orgânica do solo após a aplicação do resíduo de algodão compostado proveniente da indústria têxtil.

O experimento foi conduzido em condições de campo no Instituto de Ciências Agrárias da Universidade Federal de Minas Gerais, sob um Argissolo Vermelho-Amarelo (PVA), com histórico de cultivo de pastagem natural sem aplicação de fertilizantes de alta solubilidade. A área experimental utilizada foi de $150 \mathrm{~m}^{2}$ disposta em um delineamento em blocos casualizados. Os tratamentos foram constituídos por cinco doses de resíduo de algodão compostado proveniente da indústria têxtil $(0,20,40$, 60, 80t ha-1) com cinco repetições, totalizando 120 plantas por parcela experimental. O composto orgânico utilizado foi aplicado e incorporado no sulco de plantio 30 dias antes do plantio do feijoeiro.

A análise química e física do solo, na camada de 0-20cm, antes da aplicação do composto orgânico, conforme método descrito pela EMBRAPA (1999), apresentou os seguintes resultados: $\mathrm{pH}$ em água: 5,9; P (Mehlich): 1,1mg dm${ }^{-3}$; K: 94mg dm $\mathrm{m}^{-3}$; Ca: 1,5cmol $\mathrm{dm}^{-3}$; Mg: 0,6cmol dm ${ }^{-3}$; Al: $0,2 \mathrm{cmol} \mathrm{dm}^{-3} ; \mathrm{H}+\mathrm{Al}$; $1,10 \mathrm{cmol} \mathrm{dm}^{-3}$; MOS: $1,1 \mathrm{dag} \mathrm{kg}^{-1}$; teor de argila: 47,3dag $\mathrm{kg}^{-1}$.

O resíduo do algodão proveniente da indústria têxtil, denominado de micropó, sendo constituído predominantemente por pequenos fragmentos de fibra que são descartados na fiação, não recebeu nenhum tratamento químico na indústria e apresentou os seguintes resultados, de acordo com a metodologia de TEDESCO et al. (1995): pH: 6,6; umidade: $60 \mathrm{~g} \mathrm{~kg}^{-1}$; N-total: 22,1 $\mathrm{g} \mathrm{kg}^{-1}$; P: 6,3g kg ${ }^{-1}$; K: 2,1 $\mathrm{g} \mathrm{kg}^{-1}$; Ca: 12,8g kg-1 $\mathrm{Mg}$ : 3,6g kg-1; S: 0,3g kg-1 B: 60,3mg kg-1; Cu: 18,3mg kg-1; Mn: 77,6mg kg-1; Zn: 41,3mg kg-1 ; Fe: 93,5mg kg-1; relação C/N: 11,7/1; COT: 5,3dag kg ${ }^{-1}$; MO: 9,2dag kg ${ }^{-1}$.

O composto orgânico foi obtido pelo processo de compostagem. Para tanto, as medas de compostagem foram construídas nas dimensões 3,5m x 2,5m x 1,5m, sem adição de aditivos e mantidas a céu aberto, uma vez que, na região do presente estudo, ocorre elevada irregularidade pluvial e veranicos de longa duração. As medas de compostagem foram revolvidas de acordo com a necessidade, tendo em vista o controle da temperatura e da umidade monitoradas, respectivamente, por termômetro de mercúrio e pela observação do comportamento físicomecânico da massa a cada período de 24 horas.

O feijão, variedade carioca 'Pérola', foi semeado manualmente. Para o controle das pragas, aplicaram-se soluções alternativas de nim (Azadirachta indica) e pimenta malagueta (Capsicum frutescens) nas doses de $2 \mathrm{~kg}$ de frutas inteiras por 15 litros de água e $0,5 \mathrm{~kg}$ de pimenta vermelha em quatro litros de água juntamente com cinco colheres de sabão de coco em pó, respectivamente, utilizando-se um pulverizador manual para a aplicação. Com relação às doenças, nenhuma medida de controle foi adotada, uma vez que não foram constatados danos econômicos. Efetuaramse também capinas com auxílio de enxadas manuais a fim de manter a cultura livre de plantas espontâneas. Durante todo o experimento foi utilizada irrigação por aspersão de acordo com a necessidade da cultura.

Na colheita, a parte aérea do feijoeiro foi separada em caule, folhas e grãos, que foram secos em estufa de circulação forçada de ar à temperatura entre 65 e $70^{\circ} \mathrm{C}$ até peso constante para determinação da produção da matéria seca da parte aérea (MSPA) e de grãos.

Foram avaliadas a produção de matéria seca da parte aérea (caule + folhas), o stand final, o número de vagens por planta, a produção de grãos $\left(\mathrm{kg} \mathrm{ha}^{-1}\right)$, o peso de 100 grãos (g) e os valores de $\mathrm{pH}$ e a matéria orgânica do solo (MOS) após o cultivo da cultura. Os resultados obtidos foram submetidos à análise de variância, e as médias foram submetidas à análise de regressão. O teste " $t$ ” foi utilizado para testar os coeficientes da regressão nos níveis de probabilidade de $5 \%$ e $1 \%$.

A aplicação do resíduo de algodão compostado promoveu aumentos na produção de matéria seca da parte aérea (MSPA), no número total de vagens, na produção de grãos, no peso de 100 sementes, no pH do solo e no teor de MOS (Figura 1). No entanto, a adição desse resíduo não influenciou o stand final de plantas.

Com relação à produção de MSPA (Figura $1 \mathrm{~A})$, houve resposta linear à adição do composto orgânico. A cada tonelada de resíduo de algodão houve um aumento na produção de MSPA de 0,23g. Essa influência no desenvolvimento da planta pode ser explicada pela aplicação do resíduo de algodão compostado que, além do P e B, elementos importantes para o feijoeiro, é fornecedor de outros nutrientes como $\mathrm{Ca}, \mathrm{K}$ e Mg. Além disso, os benefícios do resíduo de algodão sobre a produção de MSPA devem estar relacionados com a melhoria de outros constituintes da fertilidade do solo. Nesse sentido, RAIJ (1991) relata que a adição de um composto orgânico ao solo é fundamental na construção e manutenção da fertilidade do solo, uma vez que influencia inúmeras características, dentre elas, a liberação lenta de P, N e S e a melhoria da capacidade tampão do solo. 


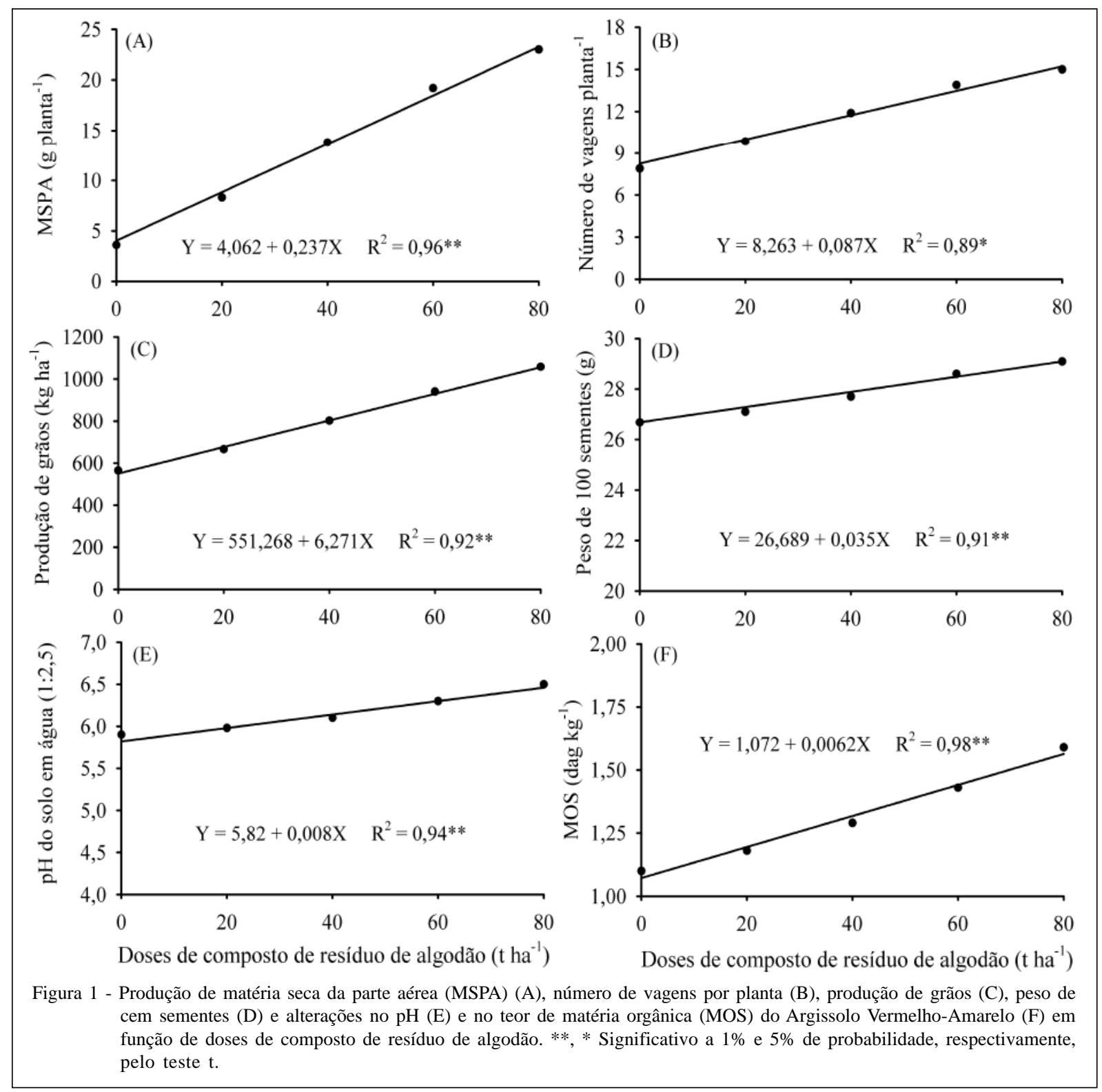

O número de vagens, a produção de grãos por planta e o peso de cem sementes também aumentaram linearmente com as doses de resíduo de algodão compostado (Figuras 1B, 1C e 1D). O número de vagens por planta contribuiu para o aumento da produção de grãos, pois esse componente é o que normalmente mais se correlaciona com essa variável (RAMOS JÚNIOR et al., 2005). Resultados semelhantes foram observados por SILVA \& SILVEIRA (2000), os quais avaliaram o feijoeiro em diferentes sistemas agrícolas de produção. Desse modo, LEMOS et al. (2004) afirmam que a produtividade de grãos está correlacionada com o número de vagens por planta e a massa de grãos, que são, portanto, variáveis importantes na seleção de variedades produtivas.

Ocorreu um incremento na ordem de 6,3kg ha $^{-1}$ de grãos para cada tonelada de composto adicionado ao solo, obtendo-se na dose máxima a produção de 1,053kg ha-1 (Figura 1C). Os valores obtidos das variáveis avaliadas no feijoeiro, neste experimento, foram superiores aos encontrados por CUNHA et al. (2005), trabalhando com a mesma variedade no sistema convencional de preparo do solo e utilizando fertilizantes minerais. De acordo com CHAGAS et al. (1999), a recomendação mineral para a cultura do feijoeiro com baixo nível tecnológico é de 
40, 70 e $30 \mathrm{~kg} \mathrm{ha}^{-1}$ para $\mathrm{N}, \mathrm{P}_{2} \mathrm{O}_{5}$ e $\mathrm{K}_{2} \mathrm{O}$, respectivamente. Dessa forma, os resultados obtidos no presente trabalho indicam a potencialidade do composto obtido a partir do resíduo de algodão como fonte de nutrientes para o feijoeiro, uma vez que a maior dose aplicada do composto forneceu 141, 115 e $81 \mathrm{~kg} \mathrm{ha}^{-1}$ de $\mathrm{N}, \mathrm{P}_{2} \mathrm{O}_{5}$ e $\mathrm{K}_{2} \mathrm{O}$, respectivamente. A comparação entre rendimentos alcançados no sistema orgânico e no sistema convencional torna-se útil, pois, no segundo, o aporte de insumos e agrotóxicos é grande, ficando em torno de $33 \%$ do custo de produção de uma saca de feijão (SOARES et al., 2005). Além disso, no sistema convencional, malefícios causados ao produtor, ao consumidor e ao meio ambiente têm sido relatados quando esses insumos não são utilizados adequadamente (CARVALHO \& WANDELEY, 2007).

Verificou-se que o aumento da dose de composto de resíduo de algodão promoveu pequena elevação linear no pH do solo (Figura 1E). Esse resultado decorre da utilização de um composto orgânico com pH maior que o pH do solo e também do fato que ânions orgânicos solúveis (R-COO- e R-O') dos compostos orgânicos, que, ao serem liberados, podem adsorver $\mathrm{H}^{+}$da solução do solo por meio de reação de troca, elevando, assim, o pH do solo (MANTOVANI et al., 2005).

Também houve um aumento linear no teor de matéria orgânica do solo (MOS) (Figura 1F) com a aplicação do composto. Cabe ressaltar que o método de Walkley-Black modificado por YEOMANS \& BREMNER (1988), o qual foi utilizado para a determinação da MOS, não separa a fração orgânica incorporada ao solo do material ainda não oxidado, embora, na época de coleta das amostras do solo, não tenham sido observados resquícios do composto de resíduo de algodão utilizado. Para a maior dose aplicada (80t ha-1), o teor de MOS apresentou aumento de $45 \%$, cujo aporte proporcionado é especialmente importante para os solos da região Norte de Minas Gerais, que, por apresentar elevadas temperaturas ao longo do ano, proporciona teores baixos de MOS. No entanto, a manutenção de altos teores de matéria orgânica pela adição de composto de resíduo de algodão dependerá de aplicações sucessivas deste, visto que os efeitos sobre os teores de MOS podem ser temporários em decorrência da decomposição da matéria orgânica ser extremamente rápida na região. Nesse sentido, MIELNICZUK et al. (2003) mencionam que a ocorrência de temperaturas elevadas resulta em altas taxas de decomposição dos resíduos vegetais e da MOS e que os Argissolos, além de promoverem menor estabilidade química da MOS, apresentam também menor capacidade de proteção física da matéria orgânica adicionada ao solo.
Verificou-se que a aplicação do resíduo de algodão compostado promoveu melhoria nas características produtivas do feijoeiro submetido ao manejo orgânico e elevou os valores de $\mathrm{pH}$ e matéria orgânica do solo. Desse modo, o composto utilizado mostrou-se como uma alternativa para a adubação da cultura.

\section{REFERÊNCIAS}

CARVALHO, W.P.; WANDERLEY, A.L. Avaliação de cultivares de feijão (Phaseolus vulgaris) para o plantio em sistema orgânico no distrito federal. Ciência e Agrotecnologia, v.31, n.3, p.605-611, 2007. Disponível em: <http://www.scielo.br/ scielo.ph p ? s cript = sci_art text \& pid = S 1413 $70542007000300002 \& \operatorname{lng}=\mathrm{en} \& \mathrm{nrm}=\mathrm{iso}>$. Doi: $10.1590 /$ S1413-70542007000300002.

CHIARADIA, A.C.N.; GOMES, J.C. Feijão: química, nutrição e tecnologia. Viçosa: Fundação Arthur Bernardes, 1997. 180p.

COSTA, M.S.S.M. et al. Compostagem de resíduos da indústria de desfibrilação de algodão. Engenharia Agrícola, v.25, n.2, p.540-548, 2005. Disponível em: <http://www.scielo.br/ s c i e lo.ph p ? s c ri p t = s c i_art text \& pid = S $0100-$ $69162005000200028 \& \operatorname{lng}=$ en $\&$ nrm $=$ iso\&tlng $=p t>$. Doi: 10.1590/S0100-69162005000200028.

CHAGAS, J.M. et al. Feijão. In: RIBEIRO, A.C. et al. COMISSÃO DE FERTILIDADE DO SOLO DO ESTADO DE MINAS GERAIS - CFSEMG. Recomendação para o uso de corretivos e fertilizantes em Minas Gerias: 5.aprox. Viçosa: MG, EMBRAPA/UFV/SBCS, 1999. Cap.18, p.306-307.

CUNHA, J.P.A.R. et al. Avaliação de pontas de pulverização hidráulicas na aplicação de fungicida em feijoeiro. Ciência Rural, v.35, n.5, p.1069-1074, 2005. Disponível em: <http:/ /www.scielo.br/scielo.php?script=sci_arttext\&pid=S0103$84782005000500013 \& \operatorname{lng}=\mathrm{e} \& \mathrm{nrm}=\mathrm{i} \operatorname{so} \& \operatorname{lng}=\mathrm{e}>$. Doi: 10.1590/S0103-84782005000500013.

EMPRESA BRASILEIRA DE PESQUISA AGROPECUÁRIA. Embrapa Solos, Embrapa Informática Agropecuária. Manual de análises químicas de solos, plantas e fertilizantes. Brasília: Embrapa Comunicação para Transferência de Tecnologia, 1999. 370p.

LEMOS, L.B. et al. Características agronômicas e tecnológicas de genótipos de feijão do grupo comercial Carioca. Pesquisa Agropecuária Brasileira, v.39, n.4, p.319-326, 2004. Disponível em: <http://www.scielo.br/scielo.php?pid=S0100204X2004000400004\&script $=$ sci_arttext\&tlng=pt $>$. Doi: 10.1590/S0100-204X2004000400004.

MANTOVANI, J.R. et al. Alterações nos atributos de fertilidade do solo adubado com composto de lixo urbano. Revista Brasileira de Ciência do Solo, v.29, n.5, p.817-824, 2005. Disponível em: $<$ http://www.scielo.br/scielo.php?script=sci_arttext\&pid=S010006832005000500017\&lng=en\&nrm=iso\&tlng=pt $>$. Doi: 10.1590/ S0100-06832005000500017.

MIELNICZUK, J. et al. Manejo de solo e culturas e sua relação com estoques de carbono e nitrogênio do solo. In: CURI, N. et 
al. (Eds.). Tópicos em ciência do solo. Viçosa, MG, Sociedade Brasileira de Ciência do Solo, 2003. V.3, p.209-248.

MELLO, S.C.; VITTI, G.C. Desenvolvimento do tomateiro e modificações nas propriedades químicas do solo em função da aplicação de resíduos orgânicos, sob cultivo protegido. Horticultura Brasileira, v.20, n.2, p.200-206, 2002. Disponível em: <http:// w w w. s c i e lo.b r / s c i e lo.ph p ? p i d = S 0102 05362002000200017\&script=sci_arttext\&tlng=pt>. Doi: 10.1590/ S0102-05362002000200017.

RAIJ, B. Fertilidade do solo e adubação. Piracicaba, Ceres, Potafos, 1991. 343p.

RAMOS JÚNIOR, E.U. et al. Componesntes de produção, produtividade de grãos e características tecnológicas de cultivares de feijão. Bragantia, v.64, n.1, p.75-82, 2005. Disponível em:<http:/ /www.scielo.br/scielo.php?script=sci_arttext\&pid=S000687052005000100008>. Doi: 10.1590/S0006-87052005000100008.

SEITER, S.; HORWATH, W.R. Strategies for managing soil organic matter to supply plans nutrition. In: MAGDOFF, F.;
WEIL, R.R. (Ed.). Soil organic matter in sustainable agriculture. London: CR PRESS, 2004. p.269-293.

SILVA, C.C.; SILVEIRA, P.M. Influência de sistemas agrícolas na resposta do feijoeiro (Phaseolus vulgaris L.) irrigado à adubação nitrogenada em cobertura. Pesquisa Agropecuária Tropical, v.30, n.1, p.86-96, 2000.

SOARES, D.M. et al. Estimativa de custo de produção de feijão: coeficientes técnicos, custos, rendimentos e rentabilidade. In: CONGRESSO NACIONAL DE PESQUISA DE FEIJÃO, 8., 2005, Goiânia, Goiás. Anais... Goiânia: Embrapa, 2005. p.881883.

TEDESCO M.J. et al. Análise de solo, planta e outros materiais. Porto Alegre: UFRGS, 1995. 174p.

YEOMANS, J.C.; BREMNER, J.M. A rapid and precise method for routine determination of organic carbon in soil. Communications in Soil Science and Plant Analysis, v.19, n.3, p.1467-1476, 1988. 